Revista peruana de biología 26(1): 135 - 142 (2019) doi: http://dx.doi.org/10.15381/rpb.v26i1.15917 ISSN-L 1561-0837; elSSN: 1727-9933

Universidad Nacional Mayor de San Marcos

\section{Evaluación de la capacidad bactericida de ex- tractos vegetales de distinta polaridad de Drimys granadensis}

\section{NOTA CIENTÍFICA}

$\begin{array}{ll}\text { Presentado: } & 17 / 08 / 2018 \\ \text { Aceptado: } & 24 / 02 / 2019 \\ \text { Publicado online: } & 30 / 03 / 2019\end{array}$

\section{Correspondencia:}

1, 2, 4 Fundación Universidad de América. Avenida Circunvalar No. 20-53. Bogotá, Colombia

3 Jardín botánico de Bogotá José Celestino Mutis. Avenida calle 63 \# 68-95. Bogotá, Colombia. Dirección postal: 111071

*Autor para correspondencia

Email DCS: daniela.cuervo19@gmail.com Email JVC: julian.vanegas1207@gmail.com Email DCB: dcorzo@jbb.gov.co

Email FCM: felipe.correa@profesores.uamerica.edu.co

Citación:

Cuervo Salcedo D., J. Vanegas Campos, D. Corzo Barragán y F. Correa Mahecha. 2019. Evaluación de la capacidad bactericida de extractos vegetales de distinta polaridad de Drimys granadensis. Revista peruana de biología 26(1): 135 - 142 (Febrero 2019). doi: http://dx.doi.org/10.15381/rpb.v26i1.15917

Palabras clave: Drimys granadensis; actividad antibacteriana; extractos vegetales; fraccionamiento por polaridad creciente; microorganismos.

Keywords: Drimys granadensis; bacterial growth inhibition; vegetable extracts; increasing polarity fractions; microorganisms.

\section{Evaluation of the bactericidal capacity of vegetable extracts of Drimys granadensis with different polarities}

\section{Daniela Cuervo Salcedo* ${ }^{1}$, Julián Vanegas Campos ${ }^{2}$, Diana Corzo Barragán ${ }^{3}$ y Felipe Correa Mahecha ${ }^{4}$}

1, 2, 4 Fundación Universidad de América, Bogotá, Colombia

3 Jardín botánico de Bogotá José Celestino Mutis, Colombia.

\section{Resumen}

Empleando el método de maceración en frío y fraccionamiento con solventes de polaridad creciente, se obtuvo cuatro extractos vegetales de distinta polaridad en las hojas de Drimys granadensis: Muy apolar (MA), apolar (A), polar (P) y Muy polar (MP), los cuales se obtuvieron al utilizar hexano, cloroformo, acetona y metanol para el fraccionamiento correspondiente. Una vez se obtuvieron los extractos, se siguió el protocolo de Minimum Inhibitory Concentration test (MIC) para determinar la concentración mínima a la cual se inhibe el crecimiento bacteriano, frente a dos cepas bacterianas Gram positivas: Staphylococcus aureus y Staphylococcus epidermis; y dos Gram negativas: Klebsiella pneumoniae y Escherichia coli. Como resultado se obtuvo que la fracción polar $(P)$ fue la más efectiva, inhibiendo el crecimiento de todas las cepas bacterianas evaluadas a partir de una concentración de $15 \mathrm{mg} / \mathrm{mL}$.

\section{Abstract}

Applying a cold maceration method and a fractioning with polar increasing solvents, four vegetable extracts of Drimys granadensis leaves were obtained: Very nonpolar $(\mathrm{MA})$, nonpolar $(\mathrm{A})$, polar $(\mathrm{P})$ and very polar $(\mathrm{MP})$; each one of them were obtained using hexane, chloroform, acetone and methanol correspondingly. Afterwards we followed the Minimum Inhibitory Concentration test (MIC) to determine the lowest concentration to inhibit the bacterial growth of two Gram positive strains: Staphylococcus aureus and Staphylococcus epidermis; and two Gram negative strains: Klebsiella pneumoniae and Escherichia coli. As a result, the polar fraction (P) was the most effective one by inhibiting the growth of all bacterial strains with a minimum concentration of $15 \mathrm{mg} / \mathrm{mL}$. 


\section{Introducción}

Drimys granadensis L.f., 1781 (Winteraceae), conocida comúnmente como "canelo de páramo" o "palo de ají", se caracteriza por ser un árbol con una altura máxima de 12 metros y flores blancas (Marín \& Parra 2015) de aroma fuerte y sabor picante, en sus hojas y tallos (de ahí su nombre común); este árbol crece en la región de los páramos altoandinos colombianos, especialmente en departamentos como Antioquia, Boyacá, Caldas, Cundinamarca, entre otros, a una altura entre 1800 y 3900 msnm (Bernal et al. 2015) (Ver figura 1).

Drimys granadensis es la especie más representativa en su familia, sus primeros registros datan desde el siglo XVI y sus estudios se enfocan principalmente en sus hojas (OPEPA 2016), las cuales han sido ampliamente utilizadas en la medicina alternativa como diurético y para combatir dolor de estómago, la constipación, la diarrea y sarna (Standley 1937, citado por Cicció 1996-1997).

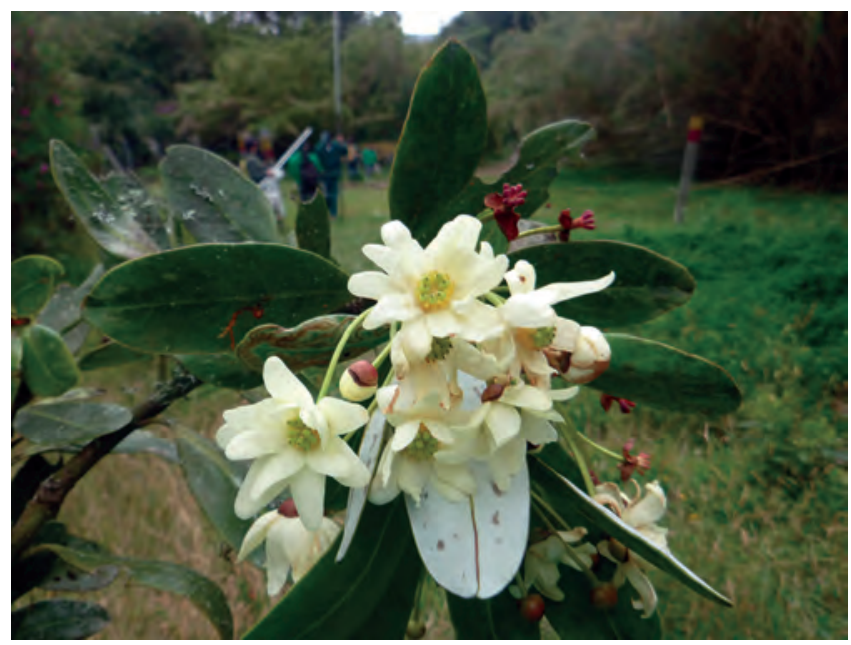

Figura 1. Planta de Drimys granadensis Foto (C): Carlos Suárez.

En Costa Rica, Ciccio (1996) extrajo el aceite esencial de hojas de D. granadensis por hidrodestilación y logró identificar 42 componentes en donde abundan los monoterpenos oxigenados. De manera similar, Gaviria et al. (2011) emplearon la misma técnica para la obtención del aceite esencial de D. granadensis en Colombia, identificando un total de 85 componentes, donde abundan los sesquiterpenos oxigenados. Se puede evidenciar diferencias de composición en el aceite esencial entre la variedad colombiana y costarricense, las cuales puede atribuirse a rasgos genéticos y a la composición del suelo en cada país (CONABIO 2006).

Adicionalmente, Gaviria et al. (2011) evaluaron de manera simultánea su actividad antibacteriana, mediante la prueba de difusión en discos de Kirby-Bauer. Como resultado se determinó que el aceite esencial de D. granadensis posee propiedades inhibitorias del crecimiento en ocho cepas bacterianas, tres gram negativas: Salmonella enteritidis, Pseudomonas aureginosa y Escherichia coli; y cinco gram positivas: Listeria monocytogenes, Staphylococcus aureus (dos tipos distintos), Bacillus cereus y Staphylococcus epidermis.
Por otro lado, Dueñas (2017) realizó un ensayo de citoxicidad en diferentes concentraciones del extracto etanólico de las hojas de D. granadensis, frente al modelo de Artemia salina, dando como resultado que la concentración letal media fue de $17.57 \mathrm{mg} / \mathrm{mL}$, considerada como alta toxicidad en organismos eucariotas.

Teniendo en cuenta el potencial antimicrobiano y la elevada toxicidad de los extractos vegetales de la especie, se desea aprovechar estas propiedades para aplicarlas en productos de uso doméstico. De este modo, se plantea determinar la concentración mínima inhibitoria de cuatro fracciones de distinta polaridad del extracto, con el propósito de identificar el grupo de moléculas (es decir, la fracción) que posee una mayor actividad biológica en el extracto y que sirva como un potencial ingrediente activo en la formulación de productos desinfectante de superficies. Para lograrlo, se desarrolla un fraccionamiento del extracto crudo por medio de solventes de polaridad creciente frente a bacterias Gram negativas y Gran positivas.

\section{Material y métodos}

Recolección de material vegetal y obtención de extracto: se recolectaron y seleccionaron hojas sanas de D. granadensis; en el páramo el Verjón (4³6'42.3"N 7402'17.0"W), un espécimen para identificación y testigo reposa en el herbario del Jardín Botánico de Bogotá José Celestino Mutis (JBB) bajo el código de barras JBB13555, catálogo número 13905. El material vegetal se dejó secar a condiciones de laboratorio por 8 días; posteriormente, se hizo una reducción del tamaño de las hojas en una trituradora; seguidamente, se realizó una maceración en frío con etanol al 96\% en una proporción 1:10 entre peso seco de hoja y volumen de etanol empleado (Sanabria 1997), por 8 días en un frasco ámbar tapado y sin contacto con la luz. Luego, se realizó un filtrado para continuar con el proceso de concentración sucesiva en un rotaevaporador Heidolph, mediante una destilación a una temperatura no superior a $40{ }^{\circ} \mathrm{C}$ y presión reducida de $500 \mathrm{mmHg}$. El extracto concentrado se almacenó hasta su uso en una cabina de extracción LEX C-4, mientras que el etanol recuperado se re-utilizó para una segunda maceración.

Fraccionamiento de extracto: el extracto vegetal debe tener apariencia viscosa y dura, con el mínimo de etanol. El extracto fue colocado dentro de un desecador con sílica gel durante aproximadamente 48 horas después del proceso de concentración. Se empleó la metodología de extracción sólido-líquido en frío (Lizcano \& Vergara 2008) con solventes de polaridad creciente obteniendo cuatro extractos: uno de polaridad muy baja o "Muy Apolar"(MA) empleando hexano como solvente; la fracción apolar (A) usó cloroformo como solvente; la fracción polar (P) que corresponde a la acetona como solvente y finalmente, la fracción muy polar (MP) empleó metanol como solvente.

Las fracciones pasaron por el mismo proceso de concentración en el rotaevaporador y secado en cabina de extracción y desecador con sílica gel, con el fin de asegurar la mínima cantidad de solvente en cada uno de los extractos obtenidos. 
Determinación de la Concentración Mínima Inhibitoria (MIC): se utilizó la metodología Minimum Inhibitory Concentration test (MIC) usada por los laboratorios Microchem (MICROCHEM 2017), la cual consiste en solubilizar cada una de las cuatro fracciones de extracto en dimetil-sulfóxido (DMSO) hasta formar soluciones STOCK de concentración de $300 \mathrm{mg} / \mathrm{mL}$ para cada una de las cuatro fracciones. Seguidamente, se realizaron diluciones seriadas de las soluciones Stock en una placa de 24 pozos con medio de cultivo agar Muller-Hinton hasta obtener concentraciones de 30, 15, 7.5, 3.8, 1.9 y $0.9 \mathrm{mg} /$ mL y completando $1000 \mu \mathrm{L}$ en cada uno de los pozos; este procedimiento se hizo por triplicado.

El inóculo fue preparado en solución salina al 0.85\%, con el fin de lograr una concentración microbiana de $1.5 \times 10^{6} \mathrm{UFC} / \mathrm{mL}$ (Andrews 2001), el cual fue comparado con la solución Estándar 0.5 de McFarland (Wiegand et al. 2008).

Cuando el medio de cultivo se gelatiniza, se inoculó cada pozo con $2 \mu \mathrm{L}$ de solución bacteriana, excepto en la última fila de la caja donde se realizaron los siguientes controles:

? Control negativo (-): Se añadió $100 \mu \mathrm{L}$ de DMSO, se completó a $1000 \mu \mathrm{L}$ de medio de cultivo y 2 $\mu \mathrm{L}$ de suspensión bacteriana. El objetivo de este control es asegurar que el solvente no afecta negativamente el crecimiento de la bacteria y toda acción bactericida sea por efectos del extracto.

? Control positivo (+): Se añadió $100 \mu \mathrm{L}$ de antibiótico Cloranfenicol, $900 \mu \mathrm{L}$ de medio de cultivo y $2 \mu \mathrm{L}$ de suspensión bacteriana. Al estar en presencia de antibiótico, se asegura que la bacteria no crezca y se pueda comparar con las concentraciones de extracto donde hay inhibición del crecimiento.

? ? Control del medio (CM): Se agregó únicamente $1000 \mu \mathrm{L}$ de medio de cultivo, sin inóculo de bacteria, con el fin de garantizar que el agar no esté contaminado por agentes externos.

? C Control de crecimiento (CC): Se agregó $1000 \mu \mathrm{L}$ de agar y $2 \mu \mathrm{L}$ de suspensión bacteria, con el fin de garantizar que la bacteria crece en condiciones normales, no está contaminada y se puede comparar el crecimiento de ésta con el de los extractos.

Una vez completado el procedimiento, se sellaron e incubaron las placas durante 24 horas a una temperatura de $37{ }^{\circ} \mathrm{C}$. Como se visualiza en la Figura 2, pasado este tiempo, se observa claramente el crecimiento de las colonias en ciertas concentraciones y el uso de los controles para monitorear que no haya ninguna contaminación en el medio de cultivo o en el ambiente que pueda dañar los resultados.

La efectividad de la prueba se estableció por la ausencia o presencia de microorganismos a una determinada concentración, la cual se logró observar de manera visual. Este procedimiento se realizó con las 4 fracciones frente a: Staphylococcus aureus ATCC 25923 y Staphylococcus epidermidis ATCC 1228, Klebsiella pneumoniae ATCC 300053 y Escherichia coli ATCC 25922.

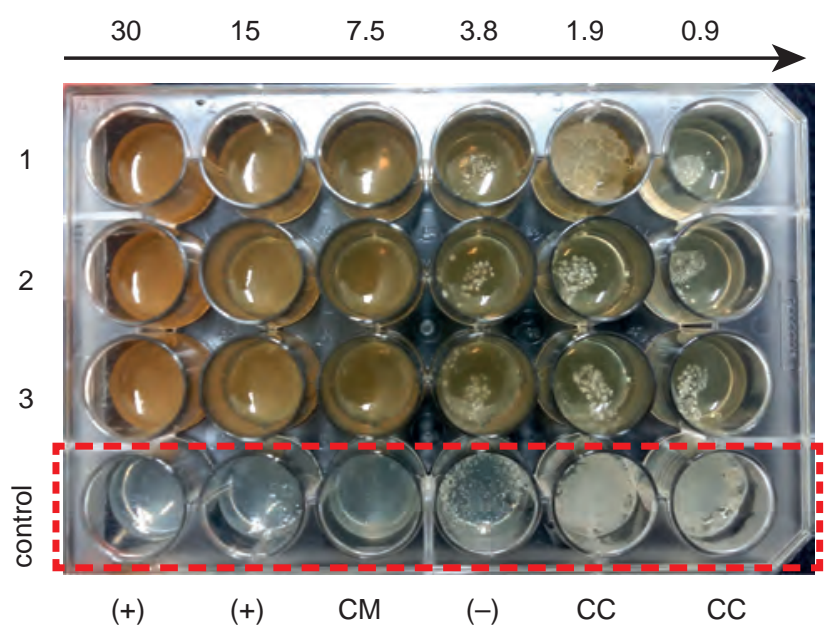

Figura 2. Placas de 24 pozos para prueba MIC.

\section{Resultados}

Durante el proceso de maceración en frío, se empleó una relación 1:10 entre la cantidad total de hojas secas y el volumen de etanol al 96\% para obtener una cantidad considerable de extracto vegetal. Como es de esperarse, este extracto de las hojas de D. granadensis se compone de muchos tipos de moléculas de diferente polaridad. Mediante el fraccionamiento a través de solventes de polaridad creciente, se pudo determinar que los compuestos de polaridad muy baja (MA) tienen un rendimiento del $12 \%$, es decir, del $100 \%$ del extracto total, un $12 \%$ fue soluble en el hexano, el solvente más apolar; de manera similar, la fracción apolar (A) tuvo un rendimiento del $46 \%$ con cloroformo; la fracción polar (P) que corresponde a la acetona como solvente, obtuvo $20 \%$ del rendimiento; y finalmente, la fracción muy polar (MP) correspondiente al metanol como solvente, tuvo un rendimiento del $15 \%$.

Teniendo en cuenta que el extracto seco vegetal es altamente viscoso, el 7\% del extracto original restante corresponde a las pérdidas debido a la cantidad que queda adherida en equipos, herramientas y demás.

Por otro lado, en la Tabla 1 se muestra los resultados obtenidos en la prueba de concentración mínima inhibitoria para cada una de las fracciones evaluadas del extracto de las hojas de D. granadensis, frente a las cepas Gram positivas. De manera similar, la Tabla 2 muestra los mismos resultados para las bacterias Gram negativas.

Según se puede observar en las tablas de resultados, las bacterias Staphylococcus aureus y Klebsiella pneumoniae presentaron una alta resistencia ante todas las fracciones evaluadas, no obstante, hubo ausencia de su crecimiento a las concentraciones de 15 y $30 \mathrm{mg} / \mathrm{mL}$, en las fracciones de acetona (P) y metanol (MP); por otro lado, las bacterias Staphylococcus epidermis y Escherichia coli mostraron inhibición del crecimiento a concentraciones 
Tabla 1. Actividad antibacteriana en bacterias Gram positivas. (+) representa presencia, mientras (-) representa ausencia.

\begin{tabular}{|c|c|c|c|c|c|c|c|c|c|c|c|c|c|}
\hline \multirow{3}{*}{$\begin{array}{l}\text { Órgano } \\
\text { Fracción } \\
\text { Réplica }\end{array}$} & & \multicolumn{12}{|c|}{ Hojas } \\
\hline & & \multicolumn{3}{|c|}{ Hexano (MA) } & \multicolumn{3}{|c|}{ Cloroformo (A) } & \multicolumn{3}{|c|}{ Acetona (P) } & \multicolumn{3}{|c|}{ Metanol (MP) } \\
\hline & & 1 & 2 & 3 & 1 & 2 & 3 & 1 & 2 & 3 & 1 & 2 & 3 \\
\hline Bacteria & & \multicolumn{12}{|c|}{ Staphylococcus aureus } \\
\hline \multirow{6}{*}{ 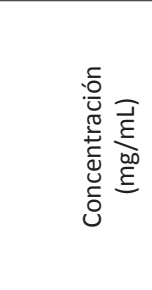 } & 30 & + & + & + & + & + & + & - & - & - & - & - & - \\
\hline & 15 & + & + & + & + & + & + & - & - & - & - & - & - \\
\hline & 7.5 & + & + & + & + & + & + & + & + & + & + & + & + \\
\hline & 3.8 & + & + & + & + & + & + & + & + & + & + & + & + \\
\hline & 1.9 & + & + & + & + & + & + & + & + & + & + & + & + \\
\hline & 0.9 & + & + & + & + & + & + & + & + & + & + & + & + \\
\hline Bacteria & & \multicolumn{12}{|c|}{ Staphylococcus epidermidis } \\
\hline \multirow{6}{*}{ 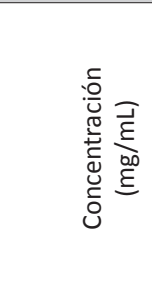 } & 30 & - & - & - & - & - & - & - & - & - & - & - & - \\
\hline & 15 & - & - & - & - & - & - & - & - & - & - & - & - \\
\hline & 7.5 & - & - & - & + & + & - & - & - & - & - & - & - \\
\hline & 3.8 & - & - & - & + & + & + & - & - & - & + & + & + \\
\hline & 1.9 & + & - & - & + & + & + & + & + & + & + & + & + \\
\hline & 0.9 & + & + & + & + & + & + & + & + & + & + & + & + \\
\hline
\end{tabular}

Tabla 2. Actividad antibacteriana en bacterias Gram negativas. (+) representa presencia, mientras (-) representa ausencia.

\begin{tabular}{|c|c|c|c|c|c|c|c|c|c|c|c|c|c|}
\hline \multirow{3}{*}{$\begin{array}{l}\text { Órgano } \\
\text { Fracción } \\
\text { Réplica }\end{array}$} & & \multicolumn{12}{|c|}{ Hojas } \\
\hline & & \multicolumn{3}{|c|}{ Hexano (MA) } & \multicolumn{3}{|c|}{ Cloroformo (A) } & \multicolumn{3}{|c|}{ Acetona (P) } & \multicolumn{3}{|c|}{ Metanol (MP) } \\
\hline & & 1 & 2 & 3 & 1 & 2 & 3 & 1 & 2 & 3 & 1 & 2 & 3 \\
\hline Bacteria & & \multicolumn{12}{|c|}{ Escherichia coli } \\
\hline \multirow{6}{*}{ 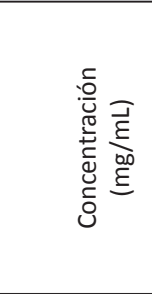 } & 30 & - & - & - & - & - & - & - & - & - & - & - & - \\
\hline & 15 & - & - & - & - & - & - & - & - & - & - & - & - \\
\hline & 7.5 & + & + & + & - & - & - & - & - & - & - & + & - \\
\hline & 3.8 & + & + & + & + & + & + & + & + & + & + & + & + \\
\hline & 1.9 & + & + & + & + & + & + & + & + & + & + & + & + \\
\hline & 0.9 & + & + & + & + & + & + & + & + & + & + & + & + \\
\hline Bacteria & & \multicolumn{12}{|c|}{ Klepsiella pneumoniae } \\
\hline \multirow{6}{*}{ 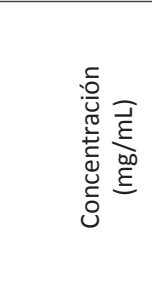 } & 30 & - & - & - & - & - & - & - & - & - & - & - & - \\
\hline & 15 & + & + & + & - & + & + & - & - & - & + & + & + \\
\hline & 7.5 & + & + & + & + & + & + & - & + & + & + & + & + \\
\hline & 3.8 & + & + & + & + & + & + & + & + & + & + & + & + \\
\hline & 1.9 & + & + & + & + & + & + & + & + & + & + & + & + \\
\hline & 0.9 & + & + & + & + & + & + & + & + & + & + & + & + \\
\hline
\end{tabular}

de 3,8 y 7,5 respetivamente, con todas las fracciones evaluadas. La bacteria Staphylococcus aureus demostró la de mayor resistencia, debido a que su crecimiento bacteriano no se ve inhibido ni siquiera a la máxima concentración del protocolo, que corresponde a $30 \mathrm{mg} / \mathrm{mL}$ para la fracciones apolares de hexano (MA) y cloroformo (A).

En la Figura 3 se puede observar gráficamente los resultados de la concentración mínima de inhibición por cada una de las cepas bacterianas evaluadas. De esta manera se puede determinar las diferencias en las concentraciones mínimas inhibitorias para cada fracción frente a un mismo microorganismo.
En la Figura 4 se muestran las cuatro placas de 24 pozos donde se evidencia la inhibición del crecimiento bacteriano para la fracción de acetona en las cepas $S$. aureus, S. epidermis, K. pneumoniae y E. coli.

\section{Discusión}

La metodología de maceración en frío empleando etanol al 96\% cumplió un papel fundamental en la extracción, puesto que se obtuvo aproximadamente un $20 \%$ de rendimiento, lo cual se considera una cantidad considerable de extracto con respecto al peso total de hojas de Drimys granadensis recolectadas. La macera- 


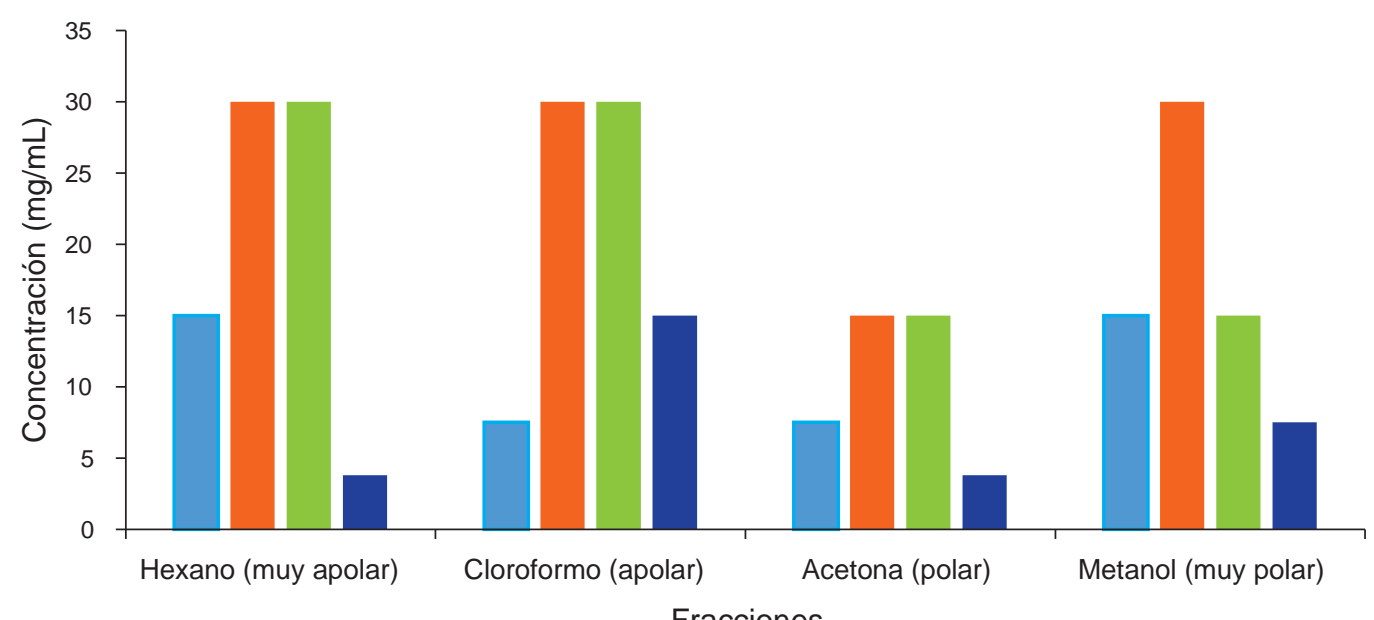

Fracciones

E. coli K. pneumoniae S. aureus $\square$ S. epidermidis

Figura 3. MIC de cada fracción por bacteria.

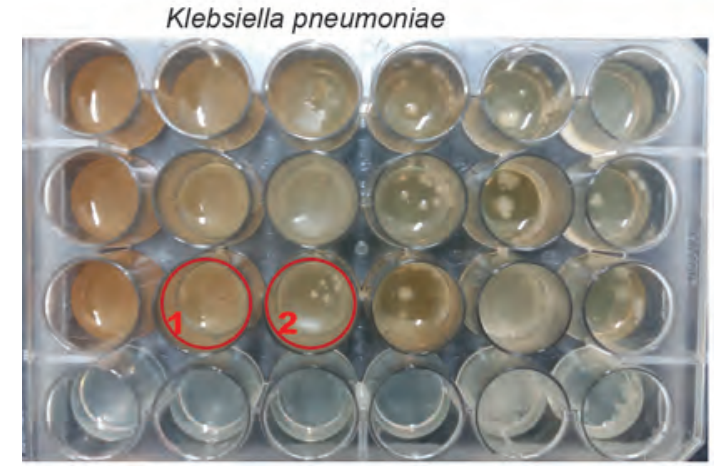

Escherichia coli

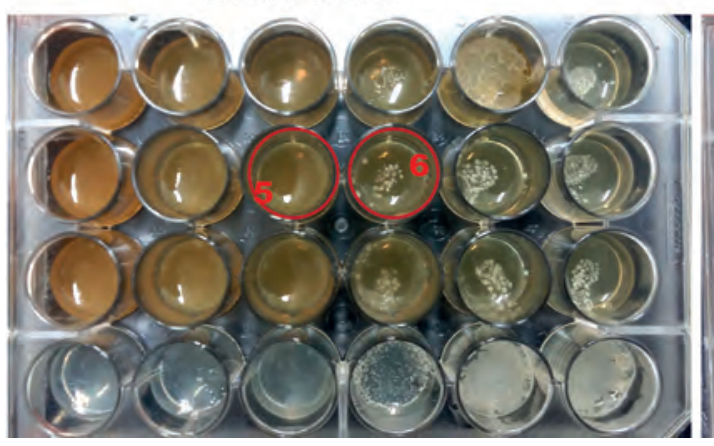

Figura 4. Resultados de la prueba MIC para la fracción de acetona. Se puede observar cómo en los circulos 2, 4 6 y 8 hay crecimiento bacteriano, mientras que en los círculos 1, 3, 5 y 7 hay inhibición y es esa concentración a la que se le conoce como la concentración mínima inhibitoria para cada bacteria. ción es un buen método de extracción cuando se busca una separación simple, sin emplear una gran cantidad de equipos y energía. No obstante, Carrión y García (2010), sostienen que la maceración tiene el inconveniente de ser un proceso que toma mucho tiempo en almacenamiento y ausencia de luz para evitar posibles reacciones fotosensibles como la degradación del extracto vegetal y también está sujeta a la saturación del solvente. Debido a esto, varios autores han optado por la extracción por fluidos supercríticos (SFE) como método de obtención del extracto vegetal. Por ejemplo, Citadin et al. (2016) emplearon la extracción por fluidos supercríticos en $D$. angustifolia, señalando que es una metodología rápida, robusta y eficiente.

Por otro lado, el fraccionamiento por solventes de polaridad creciente dio como resultado que el extracto apolar (usando cloroformo (A)) tuvo un rendimiento muy superior a los demás. En términos del proceso, esta 
característica es muy ventajosa debido a que con poca cantidad de material se logra obtener un alto porcentaje de esta fracción. Esto coincide con los resultados presentados por Gaviria et al. (2010) cuando concluyó que la variedad de Drimys granadensis colombiana tiene en su mayoría compuestos de tipo sesquiterpenos oxigenados, los cuales tienen esta característica apolar por estar presente mayoritariamente en el aceite esencial de la especie. Sin embargo, los resultados de la prueba MIC demuestran que, a pesar de su buen rendimiento, la fase apolar no es la mejor opción para emplear como agente antibacterial.

De acuerdo a la sección 1072 de la Farmacopea Americana, E. coli y $S$. aureus son dos de los 3 microorganismos más resistentes, y el presente trabajo demuestra la capacidad de inhibición del crecimiento microbiano para cada fracción de extracto. Este postulado concuerda con lo expuesto por autores como Death et al. (2001), quienes en su patente "Antimicrobial composition formulated with essential oils", enfatizan que $S$. aureus tiene la mayor resistencia de los organismos estipulados por el gobierno estadounidense para la evaluación de desinfectantes. Tomando en cuenta esta afirmación y basando este criterio en los resultados mostrados por la figura 3 , se puede decir que las fracciones de propiedades polares, empleando solventes de acetona (P) y metanol (MP) fueron las más efectivas debido a que hubo inhibición del crecimiento en estas dos cepas. La fracción obtenida empleando hexano (MA) fue muy eficaz contra $S$. epidermis debido a que inhibió su crecimiento a partir de $3.8 \mathrm{mg} / \mathrm{mL}$; sin embargo, esta fracción no logró inhibir el crecimiento de $S$. aureus en ninguna concentración (incluyendo $30 \mathrm{mg} / \mathrm{mL}$ ), al igual que la fracción de cloroformo (A).

Comparando las fracciones restantes, la fracción extraída de acetona (P) inhibe el crecimiento de $S$. epidermis a partir de una MIC de $3.8 \mathrm{mg} / \mathrm{mL}$, mientras que la de metanol en $7.5 \mathrm{mg} / \mathrm{mL}$; con respecto a E. coli y K. pneumoniae, el extracto obtenido empleando acetona $(\mathrm{P})$ tiene una MIC de $7.5 \mathrm{mg} / \mathrm{mL}$, lo cual fue similar a metanol en cuanto a $E$. coli, pero si hubo una gran diferencia en $K$. pneumoniae, donde la MIC del extracto metanólico fue de $30 \mathrm{mg} / \mathrm{mL}$; finalmente, $S$. aureus se inhibe a partir de una MIC de $15 \mathrm{mg} / \mathrm{mL}$ en ambas cepas.

Con base en los resultados de la actividad antibacteriana, se puede afirmar que los compuestos polares son los que atribuyen principalmente este potencial biológico a los compuestos medianamente polares de D. granadensis.

De manera general, el género Drimys ha demostrado poseer propiedades antimicrobianas y citotóxicas, como es también el caso de las especies Drimys angustifolia y Drimys brasiliensis, las cuales se determinó que a concentraciones de $156.3 \mu \mathrm{g} / \mathrm{mL}$ y $625 \mu \mathrm{g} / \mathrm{mL}$ respectivamente, ambas especies poseen actividad antiviral y una alta toxicidad, la cual puede causar pérdida de movilidad, diarrea, salivación, temblores, entre otros (Fonseca et al. 2012). Dentro de otra perspectiva del género Drimys, se encuentran sus usos medicinales; en el caso de las espe- cies $D$. angustifolia y D. brasiliensis incluso se ha propuesto la idea de que gracias a sus propiedades citotóxicas, su extracto puede causar muerte celular por apoptosis, lo cual puede ser un posible tratamiento para el cáncer, pero se deben realizar estudios más avanzados para confirmar esta idea (Gomes et al. 2013). El género Drimys es prometedor en muchos campos de la fitoquímica y la medicina, por lo cual es pertinente realizar estudios más específicos de cualificación y cuantificación en cuanto a este tipo de especies.

Los resultados obtenidos en la prueba de MIC para D. granadensis, dan indicio hacia posibles aplicaciones en el sector de higiene y aseo (más específicamente de desinfectantes), de las moléculas medianamente polares de la especie.

En conclusión, el presente estudio tuvo como objetivo comparar, mediante el aislamiento y la evaluación independiente de los grupos de moléculas con diferente polaridad en el extracto vegetal de Drimys granadensis, la actividad antibacteriana de los mismos, con el fin de determinar si vale la pena separar estas moléculas para obtener mejores resultados y una desinfección más efectiva. Después de realizados los estudios, consideramos que esta es una muy buena alternativa y recomendamos continuar profundizando en el tema con estudios posteriores. Sin embargo, las principales desventajas que identificamos en la técnica empleada en la presente investigación fueron que, en primer lugar, la viscosidad y las propiedades organolépticas del extracto vegetal crudo hacen que sea difícil su manipulación y fraccionamiento. Asimismo, al emplear solventes para llevar a cabo dicho fraccionamiento, no es muy favorable desde el punto de vista financiero, dado que, a pesar de que se recupera parte de estos solventes posteriormente a la concentración de los extractos, existen las pérdidas por evaporación y también se debe hacer una inversión inicial.

Por este motivo, recomendamos enfocar dichos estudios en el aceite esencial, puesto que antecedentes tales como el estudio de Gaviria et al. (2010) y Dueñas (2017) han demostrado una buena efectividad antibacteriana y adicionalmente, se facilita el proceso.

\section{Literatura citada}

Andrews J.M. 2001. Determination of minimum inhibitory concentrations. Journal of Antimicrobial Chemotherapy. Vol. 41. p. 10. https://doi.org/10.1093/jac/48. suppl_1.5

Bernal, R., S.R. Gradstein \& M. Celis (eds.). 2015. Catálogo de plantas y líquenes de Colombia. Instituto de Ciencias Naturales, Universidad Nacional de Colombia, Bogotá. http://catalogoplantasdecolombia.unal.edu.co

Carrión Jara, A. V., \& C. R. García Gómez. (2010). Preparación de extractos vegetales: determinación de eficiencia de metódica. Universidad de Cuenca. Tesis 27 - 29. http:// dspace.ucuenca.edu.ec/handle/123456789/2483

Ciccio J.F. 1996-1997. Aceites esenciales de las hojas y de los frutos verdes de Drimys granadensis (Winteraceae). Revista de Biología Tropical. 44(3)/45(1): 29-33. 
CONABIO (Comisión Nacional para el Conocimiento y Uso de la Biodiversidad). 2006. Elementos para la determinación de centros de origen y centros de diversidad genética en general y el caso específico de la liberación experimental de maíz transgénico al medio ambiente en México. Comisión Nacional para el Conocimiento y Uso de la Biodiversidad. México D.F.

Del Valle A. J.I. 1972. Introducción a la Dendrología de Colombia. Centro de Publicaciones, Universidad Nacional de Colombia. Medellín, Colombia, p. 351.

Dueñas J.T. 2017. Desarrollo de un producto bioactivo partiendo de extractos vegetales de especies alto andinas. Fundación Universidad de América. Facultad de Ingeniería.p. 36.

Fonseca, M. et al. 2013. Biological assessment (antiviral and antioxidant) and acute toxicity of essential oils from Drimys angustifolia and D. brasiliensis. Revista Brasileira de Farmacognosia. 23 (2): 284 - 290. https://doi. org/10.1590/S0102-695X2012005000142

Citadin D.G., et al. 2016. Supercritical fluid extraction of Drimys angustifolia Miers: Experimental data and identification of the dynamic behavior of extraction curves using neural networks based on wavelets. The Journal of Supercritical Fluids. 112:81-88. https://doi. org/10.1016/j.supflu.2016.02.007

Gaviria M., et al. 2011. Chemical composition and antibacterial activity of the essential oil of Drimys granadensis L.F leaves from Colombia. Chem Biodivers. Mar; 8(3):5329. https://doi.org/10.1002/cbdv.201000170

Gomes M.R.F., R.S. Schuh, A.L.B. Jacques, O.A. Augustin, S.A.L. Bordignon, D.O. Dias, R.G. Kelmann, L.S. Koester, M.P. Gehring, F.B. Morrone, et al. 2013. Citotoxic activity evaluation of essential oils and nanoemulsions of Drimys angustifolia and D. brasiliensis on human glioblastoma (U-138 MG) and human bladder carcinoma (T24) cell lines in vitro. Revista Brasileira de Farmacognosia. 23(2):259-267. http://dx.doi.org/10.1590/ S0102-695X2012005000136.

Lizcano A. \& J. Vergara. 2008. Evaluación de la actividad antimicrobiana de los extractos etanólicos y/o aceites esenciales de las especies vegetales Valeriana pilosa, Hesperomeles ferruginea, Myrcianthes rhopaloides y Passiflora manicata frente a microorganismos patógenos y fitopatógenos. Pontificia Universidad Javeriana, Facultad de Ciencias, Bogotá. Trabajo de grado. https://www.javeriana.edu.co/biblos/tesis/ciencias/ tesis151.pdf
Marín C. \& S. Parra. 2015. Bitácora de flora: Guía visual de plantas de páramos en Colombia. Bogotá: Instituto de Investigación de Recursos Biológicos Alexander von Humboldt. 360pp.

Moncada, J. et al. 2014. Techno-economic and environmental assessment of essential oil extraction from Citronella (Cymbopogon winteriana) and Lemongrass (Cymbopogon citrus): A Colombian case to evaluate different extraction technologies. Industrial crops and products. 54: 175 - 184. https://doi.org/10.1016/j.indcrop.2014.01.035

MICROCHEM Laboratory. (En línea). Minimum Inhibitory Concentration Test (MIC). En línea. [Consultado: 24 de abril de 2017]. <http://microchemLab.com/test/minimum-inhibitory-concentration-test-mic-0>

OPEPA (Organización para la Educación y Protección Ambiental) - Canelo de páramo - Drimys granadensis. http:// www.opepa.org/index.php?option=com_content\&tas

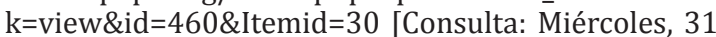
de agosto de 2016].

Sanabria-G A; S.I. López \& R. Gualdrón. 1997. Estudio fitoquímico preliminar y letalidad sobre Artemia salina de plantas colombianas. Revista Colombiana de ciencias Química Farmacéutica No. 26, 15-19. http://dx.doi. org/10.15446/rcciquifa

Wiegand, I., et al. 2008. Agar and broth dilution methods to determine the minimal inhibitory concentration (MIC) of antimicrobial substances. Nature protocols, No. 3, 163 - 175. https://doi.org/10.1038/nprot.2007.521

\section{Agradecimientos}

Los autores expresan su agradecimiento a Martha Liliana Pinzón, microbióloga del Jardín Botánico de Bogotá, a Erika Andrea Plazas y al personal de la subdirección científica del Jardín Botánico de Bogotá que colaboró con la realización del trabajo.

\section{Rol de los autores:}

Conceptualización, D.C.B. y F.C.M.; Metodología, D.C.B. y F.C.M.; Investigación, D.C.S. y J.V.C.; Redacción - Borrador original, D.C.S.; Redacción - Revisión \& Edición, D.C.S. y J.V.C. y D.C.B.; Adquisición de fondos, D.C.B.; Recursos, D.C.B.; Supervisión, D.C.B. y F.C.M.

Conflicto de intereses:

Los autores no incurren en conflictos de intereses.

Fuentes de financiamiento:

El proyecto fue financiado y supervisado por la subdirección científica del Jardín Botánico de Bogotá José Celestino Mutis.

Aspectos éticos / legales:

Este trabajo no incurrió en ningún problema ético o legal. 
